\title{
Effects of intravenous diltiazem in a rat model of experimental coronary thrombotic microembolism
}

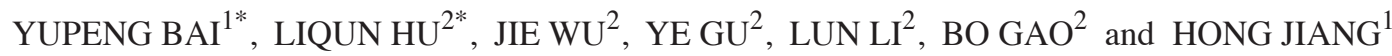 \\ ${ }^{1}$ Department of Cardiology, Renmin Hospital of Wuhan University, Wuhan 430060; ${ }^{2}$ Department of Cardiology, \\ Puai Hospital, Huazhong University of Science and Technology, Wuhan 430030, P.R. China
}

Received April 4, 2013; Accepted August 5, 2013

DOI: $10.3892 /$ etm.2013.1263

\begin{abstract}
The aim of this study was to assess the feasibility of evaluating the therapeutic effects of intravenous diltiazem in a newly established rat model of coronary thrombotic microembolism (CME). CME was induced by injecting $0.199 \mathrm{ml}$ saline containing $5 \mathrm{mg}$ of automicrothrombotic particulates $(\sim 10 \mu \mathrm{m})$ into the aorta of Sprague Dawley rats. The injection was carried out over $10 \mathrm{sec}$ using a tuberculin syringe with a 28-gauge needle. The CME model rats were randomly divided into untreated (CME, $n=38)$ and diltiazem-treated (CME+DIL, $\mathrm{n}=38)$ groups. Diltiazem $(1 \mathrm{mg} / \mathrm{ml}, 50 \mu \mathrm{g} / \mathrm{min} / \mathrm{kg})$ was intravenously injected using an infusion pump through the tail vein for $175 \mathrm{~min}, 5 \mathrm{~min}$ following the injection of the automicrothrombotic particulates. Hemodynamic measurements, echocardiography and pathohistological examinations were performed at various time-points $(3 \mathrm{~h}, 24 \mathrm{~h}$ and 7 and 28 days) postoperatively. Arteriolar thrombosis, multifocal myocardial necrosis, inflammatory cell infiltration with markedly increased myocardial tumor necrosis factor $\alpha$ (TNF- $\alpha$ ) and interleukin-6 (IL-6) expression, reduced left ventricular (LV) systolic function and increased plasma von Willebrand factor (vWF), endothelin-1 (ET-1) and serum c-troponin I (c-TnI) levels (indicating vascular endothelial injury and myocardial necrosis) were observed in the CME model rats. These pathological responses in CME rats were partly attenuated by intravenous diltiazem treatment. The present CME model is suitable for evaluating the therapeutic effects of intravenous diltiazem; intravenous diltiazem treatment significantly improved cardiac function through alleviating inflammatory responses and microvascular thrombotic injury in this rat model of CME.
\end{abstract}

Correspondence to: Professor Hong Jiang, Department of Cardiology, Renmin Hospital of Wuhan University, 238 Jiefang Road, Wuhan, Hubei 430060, P.R. China

E-mail: jianghong58@gmail.com

*Contributed equally

Key words: coronary thrombosis, microembolism, no flow phenomenon, diltiazem

\section{Introduction}

Coronary thrombotic microembolism (CME) may be induced by spontaneous plaque rupture and disrupted plaque components produced during coronary interventions. CME has been shown to lead to myocardial microinfarcts, as reflected by elevated creatine kinase (CK) and troponin I (TnI) (1-7), which may partly contribute to impaired microvascular perfusion and result in the 'slow' or 'no-reflow' phenomenon (6-10). A number of efforts, including intravascular thrombolysis drug application and thrombosis suction, have been attempted for the prevention and treatment of CME and CME-induced myocardial impairment (11-16). Previous studies have demonstrated that calcium antagonists are capable of relieving microvascular spasm $(17,18)$ and that the intravascular application of diltiazem may attenuate coronary artery spasms in patients with microvascular angina or acute myocardial infarction with 'no-reflow' phenomenon $(19,20)$. In our previous experimental study, a rat CME model was established by the aortic injection of automicrothrombotic particulates (9). In the present study, we examined whether this model is suitable for testing and reflecting the therapeutic effects of drugs that may be capable of attenuating coronary microembolization. It was hypothesized that intravenous diltiazem, an agent with proven clinical effectiveness in reducing coronary microembolization, may attenuate the cardiac dysfunction and pathological changes in the rat CME model.

\section{Materials and methods}

Animals. A total of 152 adult male Sprague Dawley rats (weight, 250-350 g; age, 12 weeks) were used in the present study. Thirty-two rats were used for the dose-finding pilot study. Forty rats were subjected to an aortic saline injection (sham group, $\mathrm{n}=40$ ) and 80 rats underwent procedures to induce CME, as described previously (9). Briefly, blood $(0.5 \mathrm{ml})$ was obtained from the ventral tail artery of all rats 1 day prior to surgery (21). The blood was left to clot for $1 \mathrm{~h}$ and then dried overnight at $37^{\circ} \mathrm{C}(9,22)$. The dried blood was fragmented into thrombotic particulates with a Sabi Crush Easy Pill Smasher (SABI Co., Palo Alto, CA, USA) for 5 min. Subsequently, $5 \mathrm{mg}$ thrombotic particulates were dissolved in $0.2 \mathrm{ml}$ saline and filtered through a $45-\mu \mathrm{m}$ metal filter. The filtrates were collected and the mixed solution $(1 \mu \mathrm{l})$ was utilized for a 
particulate number count and size determination using a TS-M2 micrometer (OPLENIC Manufacturer, HangZhou, China). Examination revealed that the number of particulates with a diameter of $10-45 \mu \mathrm{m}$ was $\sim 600,000$, whereas the majority of particulates $(>90 \%, \sim 16,000,000)$ had a diameter $<10 \mu \mathrm{m}$. The remaining $0.199 \mathrm{ml}$ filtrates were injected into sodium pentobarbital-anesthetized $(50 \mathrm{mg} / \mathrm{kg}$, i.p.) rats. The second intercostal space was exposed through parasternotomy and a microretractor was used to separate the second and third rib in order to adequately expose the operating region under strictly aseptic conditions. Following the removal of the pericardium, the ascending aorta was visualized. The ascending aorta was temporarily clamped by a microvascular clip and $0.199 \mathrm{ml}$ filtrate or $0.2 \mathrm{ml}$ saline was injected into the aorta over $10 \mathrm{sec}$ using a 28 -gauge tuberculin syringe. The mean quantity of hemorrhage ranged from 0.5 to $1.0 \mathrm{ml}$ following injection into animals without massive hemorrhage. During surgery, the animals were monitored with electrocardiograms using standard lead II through subcutaneous needle electrodes. Penicillin (800,000 IU, i.p.) was administered daily for 7 days to animals studied at 7 and 28 days after the aortic injection of automicrothrombotic particulates or saline. Four rats died immediately after the injection of automicrothrombotic particulates (three due to large hemorrhage and one due to malignant arrhythmia). The CME model rats that survived were randomly assigned to the untreated (CME group, $n=38$ ) or diltiazem-treated CME groups $(\mathrm{CME}+\mathrm{DIL}$ group, $\mathrm{n}=38)$. In the latter group, diltiazem $(1 \mathrm{mg} / \mathrm{ml})$ was intravenously injected at an infusion rate of $50 \mu \mathrm{g} / \mathrm{min} / \mathrm{kg}$ using an infusion pump (Perfusor®, TCI-II; Guangxi Veryark Technology Co., Ltd., Guangxi, China) through the tail vein for $175 \mathrm{~min}, 5 \mathrm{~min}$ following the injection of automicrothrombotic particulates. The dose of drug used in the main study was selected based on the results of the pilot study (as described in Results). The rats were examined and sacrificed at $3 \mathrm{~h}, 24 \mathrm{~h}, 7$ days and 28 days postoperatively ( $\mathrm{n}=8-10$ at each time point).

Experiments were approved by the Tongji Medical College Council on the Animal Care Committee of Huazhong University of Science and Technology (Wuhan, China). Animals were maintained in accordance with the Guide for the Care and Use of Laboratory Animals published by the US National Institute of Health (NIH Publication No.85-23, revised 1996).

Transthoracic echocardiography. Prior to and 28 days following surgery, rats in the 28 days group were anesthetized (sodium pentobarbital, $50 \mathrm{mg} / \mathrm{kg}$, i.p.) and lightly secured to a warming pad in the supine position, and their precordium was shaved. Transthoracic echocardiography was performed using a cardiac ultrasound machine with a $11.2 \mathrm{MHz}$ transducer (Vivid 7; GE Healthcare, Fairfield, CT, USA). The heart was first imaged in the two-dimensional mode in the parasternal long-axis and parasternal short-axis views. Left ventricular (LV) areas were measured from the transverse sections and the LV short-axis lengths were used to calculate LV end-systolic diameters (LVESDs) or volumes (LVESVs) and end-diastolic diameters (LVEDDs) or volumes (LVEDVs) using the modified Simpson's rule formula. The inner endocardial margin defined the LV lumen and the LVEF was derived using the following formula: $\mathrm{LVEF}=(\mathrm{LVEDV}-\mathrm{LVESV}) / \mathrm{LVEDV} \times 100 . \mathrm{LV}$ thickness was measured from the M-mode recording at the mid-papillary level. The results from three different cardiac cycles were averaged.

Hemodynamic measurements. Hemodynamic measurements were performed in the $3 \mathrm{~h}$ group. LV systolic pressure (LVSP) and end-diastolic pressure (LVEDP), the maximum rate of increase of LV systolic pressure (dp/dtmax) and heart rate (HR) were measured using a $1 \%$ heparinized short segment of a saline-filled PE 50 catheter connected to a solid-state miniature pressure transducer and the Philips apparatus (Integris Allura 12; Philips Healthcare, Heide, The Netherlands) (23).

Serum c-troponin I (c-TnI) measurement. Prior to sacrifice, blood $(1.0 \mathrm{ml})$ was obtained from the femoral vein of each rat in the $24 \mathrm{~h}$ group at 6 and $24 \mathrm{~h}$ postoperatively. c-TnI was measured by immunofluorescence methods and an immunofluorescence assay (OPUS, Dade Behring, Inc., Mariani Cupertino, CA, USA).

Determination of von Willebrand factor $(v W F)$ and endothelin-1 (ET-1). Blood (2.0 ml) was obtained from the femoral vein of each rat in all 4 groups ( 3 h, 24 h, 7 days and 24 days) prior to sacrifice. Blood was centrifuged at 2,000 x g and the serum vWF and ET-1 levels were determined using antibodies in an antigen-based sandwich ELISA assay (von Willebrand Factor Elisa kit, Helena Laboratories, Beaumont, TX, USA; Endothelin-1 Quantikine ELISA kit, ELISAs More Quality Reagents from R\&D Systems, Minneapolis, MN, USA).

Evaluating areas of no-flow. Three hours postinjection, a single bolus of thioflavin-S (1 ml/kg of 4\%; Sigma, St. Louis, MO, USA) was injected via the jugular vein to stain the vascular endothelium in vivo (24). One min later, the heart was stopped in the diastolic phase by an intravenous injection of potassium chloride $(1 \mathrm{ml}, 10 \%)$ and removed immediately. The atrium and right ventricle were separated from the left ventricle. The left ventricle was then placed into a $-20^{\circ} \mathrm{C}$ freezer for $5 \mathrm{~min}$ and sectioned into 10 or 11 cross-sectional slices $(1 \mathrm{~mm}$ in thickness) along the long axis using a cutting apparatus (JP40; Shanghai Shiyuan Scientific Equipment Co., Ltd., Shanghai, China). Even slices (2,4,6,8 and 10) were fixed in formalin solution and used for light microscopic and immunohistochemical analyses. Uneven slices $(1,3,5,7,9$ and 11) were irradiated with ultraviolet light (wave length, $365 \mathrm{~nm}$ ) to determine the no-flow zone (NF, area not perfused by thioflavin-S). The NF was traced and analyzed using NIH imaging software (http:// rsb.info.nih.gov/nih-image/). The ratios of NF/LV area (NF/ LV) from all examined slices were calculated and averaged.

Light microscopic analysis. LV tissue samples from the $3 \mathrm{~h}$ group were fixed in $10 \%$ buffered formalin solution for $24 \mathrm{~h}$, embedded in paraffin, cut into $4-\mu \mathrm{m}$ sections and stained with hematoxylin and eosin (H\&E), Carstair's (25) and hematoxylin basic fuchsin picric acid (HBFP) (26), respectively. An Olympus-BX41TF microscope (Olympus, Tokyo, Japan) incorporated with Image-Pro Plus 4 (Media Cybernetics, Inc., Rockville, MD, USA) was employed to observe the microthrombosis in the coronary arteriole in H\&E-stained slices. One hundred coronary arterioles with a diameter $<100 \mu \mathrm{m}$ 
were randomly observed under a microscope (magnification, x200) and the percentage of microthrombosis in these arterioles was determined. For animals studied 28 days postoperatively, hearts were embedded in paraffin, sectioned at 5- $\mu \mathrm{m}$ intervals and stained with Masson's trichrome (27). Myocardial leukocyte infiltration was observed in rats $24 \mathrm{~h}$ and 7 days postoperatively in H\&E-stained sections. Leukocytes were counted in 10 randomly selected visual fields in each section and five sections per rat were examined.

Immunohistochemical analysis. LV tissue samples from the $3 \mathrm{~h}$ group were fixed in $10 \%$ buffered formalin solution for $24 \mathrm{~h}$, embedded in paraffin and cut into $4-\mu \mathrm{m}$ sections for immunohistochemical analysis. Tissue sections were blocked with $10 \%$ normal serum for $1 \mathrm{~h}$ at $27^{\circ} \mathrm{C}$. The blocker was removed and the primary antibody, vascular smooth muscle $\alpha$-actin (VSMA- $\alpha$ ) antibody (mouse monoclonal anti-VSMA; Santa Cruz Biotechnology Inc., Santa Cruz, CA, USA) was added. The tissue sections were incubated for $15 \mathrm{~h}$ at $4^{\circ} \mathrm{C}$ and washed with PBS, then the peroxidase block was performed with $0.5 \% \mathrm{H}_{2} \mathrm{O}_{2}$ in methanol for $30 \mathrm{~min}$. The respective biotinylated secondary antibody (rabbit anti mouse IgG, Santa Cruz Biotechnology Inc.) was added and incubated for $1 \mathrm{~h}$ at $27^{\circ} \mathrm{C}$. After washing with PBS, the streptavidin peroxidase label (Zymed, San Diego, CA, USA) was added and incubated for $10 \mathrm{~min}$ at $27^{\circ} \mathrm{C}$. The sections were washed with PBS and incubated with AEC color development substrate (Zymed) for a further $10 \mathrm{~min}$ at $27^{\circ} \mathrm{C}$. Sections were washed in water and counterstained with Mayer's hematoxylin. The vascular smooth muscle was dyed claybank and the arterioles (10-50 $\mu \mathrm{m})$ were counted in 10 random fields of vision in each section, and five sections per rat were examined under a light microscope (magnification, x200). Arteriolar density (AD) was calculated using the following formula: $\mathrm{AD}=$ total arteriole number/ $10 \times 5 /$ the area of one vision $\left(\mathrm{mm}^{2}\right)$.

Western blot analysis. At 24 h, 7 days and 28 days after injection, the apex of the left ventricle was used for western blot analysis. Tissues were homogenized in PBS and centrifuged at $10,000 \mathrm{x} \mathrm{g}$ for $10 \mathrm{~min}$ at $4^{\circ} \mathrm{C}$, then $70 \mu \mathrm{g}$ supernatant was lysed in electrophoresis buffer, boiled for $10 \mathrm{~min}$ and subsequently subjected to electrophoresis on a SDS-polyacrylamide gel. The separated blots were transferred to nitrocellulose membranes and blocked for $1 \mathrm{~h}$ in TTBS buffer containing 5\% nonfat milk. The membranes were incubated overnight with primary anti-TNF- $\alpha$ or IL-6 polyclonal antibodies (TNF- $\alpha$, 1:500 dilution; IL-6, 1:200 dilution) and then with horseradish peroxidase (HRP)-conjugated rabbit anti-goat IgG antibody (1:1,000 dilution) for $2 \mathrm{~h}$ at $37^{\circ} \mathrm{C}$. Blots were detected by chemiluminescence and relative protein expression was quantified by scanning densitometry.

Statistical analyses. The data were analyzed using SPSS 13.0 (SPSS, Inc., Chicago, IL, USA). Data are presented as the mean \pm SD. Comparisons among groups and different experimental stages were first carried out using a test of homogeneity of variances and then by two-way ANOVA, Tukey's test (homogeneity of variance) and the Games-Howell test (heterogeneity of variance). A P-value of 0.05 was considered to indicate a statistically significant difference.

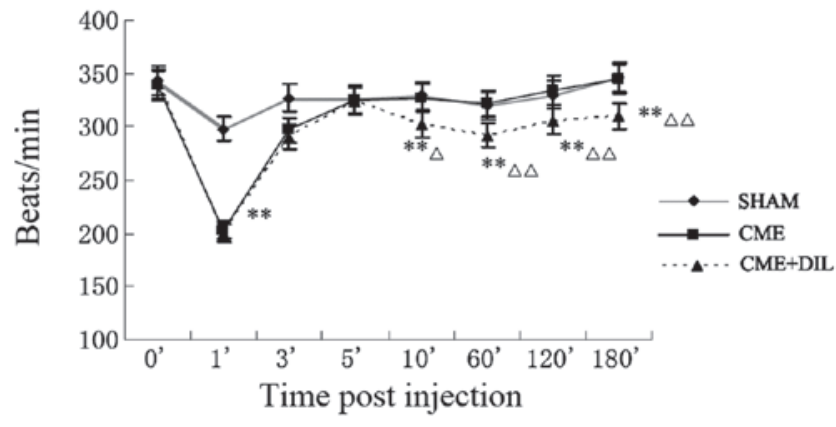

Figure 1. Heart rate changes postinjection. Following the injection of automicrothrombotic particulates, the heart rate decreased significantly at $1 \mathrm{~min}$ and returned to baseline after $5 \mathrm{~min}$ in the CME and CME+DIL groups. The heart rate was significantly lower in the CME+DIL group than in the CME group. Data are presented as the mean \pm SD. ${ }^{* *} \mathrm{P}<0.01$ vs. the SHAM group; ${ }^{\triangle} \mathrm{P}<0.05,{ }^{\triangle} \mathrm{P}<0.01$ vs. the $\mathrm{CME}$ group. $\mathrm{CME}$, coronary thrombotic microembolism; DIL, diltiazem.

\section{Results}

Pilot study. Prior to the main study, a pilot study was performed to observe the blood pressure and heart rate changes induced by various concentrations of diltiazem. In our previous study (9), thrombosis was observed at $1 \mathrm{~h}$, peaked at $3 \mathrm{~h}$ and decreased at $12 \mathrm{~h}$, while heart rate decreased significantly at $1 \mathrm{~min}$ and returned to baseline level at $5 \mathrm{~min}$ after the injection of automicrothrombotic particulates. Therefore, diltiazem was infused at doses of $10,50,100$ or $200 \mu \mathrm{g} / \mathrm{min} / \mathrm{kg}$ ( $\mathrm{n}=8$ for each dose) through the tail vein for $175 \mathrm{~min}$ with an infuser at $5 \mathrm{~min}$ after the automicrothrombotic particulate injection. The $200 \mu \mathrm{g} / \mathrm{min} / \mathrm{kg}$ dose of diltiazem significantly reduced blood pressure $(<90 \mathrm{mmHg})$ and heart rate $(<200$ beats per minute), while the $100 \mu \mathrm{g} / \mathrm{min} / \mathrm{kg}$ dose did not affect the blood pressure but significantly reduced the heart rate ( $<250$ beats per minute). Blood pressure and heart rate were not significantly affected by the 10 and $50 \mu \mathrm{g} / \mathrm{min} / \mathrm{kg}$ doses of diltiazem, and the beneficial effects of reducing the $\mathrm{NF} / \mathrm{LV}$ area were greater using $50 \mu \mathrm{g} / \mathrm{min} / \mathrm{kg}$ diltiazem compared with $10 \mu \mathrm{m} / \mathrm{min} / \mathrm{kg}$ diltiazem (5\% vs. $2 \%$ ). As a result, diltiazem at a dose of $50 \mu \mathrm{g} / \mathrm{min} / \mathrm{kg}$ was selected for the main study.

Mortality. In the sham group, 2 rats died during the perioperative period (1 due to excess anesthesia, 1 due to massive hemorrhage). The remaining 38 rats were examined at $3 \mathrm{~h}$ $(n=9), 24 \mathrm{~h}(\mathrm{n}=10), 7$ days $(\mathrm{n}=10)$ and 28 days $(\mathrm{n}=9)$. In the CME group, 3 animals died at 10 h, 26 h and 4 days postinjection, respectively. This was due to cardiac failure based on the postmortem pathological findings (pulmonary venous pleonaemia and pleural effusion). The remaining 35 rats were examined at $3 \mathrm{~h}(\mathrm{n}=9), 24 \mathrm{~h}(\mathrm{n}=9), 7$ days $(\mathrm{n}=9)$ and 28 days $(n=8)$. In the CME+DIL group, no rats died and 38 rats were examined at $3 \mathrm{~h}(\mathrm{n}=10), 24 \mathrm{~h}(\mathrm{n}=9), 7$ days $(\mathrm{n}=10)$ and 28 days $(n=9)$.

Heart rate changes. Following the injection of automicrothrombotic particulates, the heart rate decreased significantly at $1 \mathrm{~min}$ and returned to baseline level $5 \mathrm{~min}$ postinjection in the CME and CME+DIL groups, while it remained unchanged in the sham group (Fig. 1). 
Table I. Two-dimensional mode transthoracic echocardiography results.

\begin{tabular}{lllll}
\hline Variable & Status & Sham group & CME group & CME+DIL group \\
\hline LVEDD $(\mathrm{mm})$ & Pre-op & $5.66 \pm 0.59(\mathrm{n}=10)$ & $5.84 \pm 0.47(\mathrm{n}=10)$ & $5.88 \pm 0.39(\mathrm{n}=10)$ \\
& Post-op & $5.77 \pm 0.42(\mathrm{n}=8)$ & $6.65 \pm 0.61^{\mathrm{a}, \mathrm{b}}(\mathrm{n}=8)$ & $6.20 \pm 0.44(\mathrm{n}=9)$ \\
LVESD $(\mathrm{mm})$ & Pre-op & $2.88 \pm 0.24(\mathrm{n}=10)$ & $2.95 \pm 0.21(\mathrm{n}=10)$ & $2.90 \pm 0.19(\mathrm{n}=10)$ \\
& Post-op & $2.92 \pm 0.13(\mathrm{n}=8)$ & $4.58 \pm 0.45^{\mathrm{a}, \mathrm{b}}(\mathrm{n}=8)$ & $3.73 \pm 0.43^{\mathrm{a}-\mathrm{c}}(\mathrm{n}=9)$ \\
LVEDV $(\mathrm{ml})$ & Pre-op & $0.47 \pm 0.11(\mathrm{n}=10)$ & $0.48 \pm 0.10(\mathrm{n}=10)$ & $0.49 \pm 0.09(\mathrm{n}=10)$ \\
& Post-op & $0.47 \pm 0.05(\mathrm{n}=8)$ & $0.92 \pm 0.10^{\mathrm{a}, \mathrm{b}}(\mathrm{n}=8)$ & $0.71 \pm 0.10^{\mathrm{a}-\mathrm{c}}(\mathrm{n}=9)$ \\
LVESV $(\mathrm{ml})$ & Pre-op & $0.09 \pm 0.02(\mathrm{n}=10)$ & $0.09 \pm 0.01(\mathrm{n}=10)$ & $0.09 \pm 0.01(\mathrm{n}=10)$ \\
& Post-op & $0.09 \pm 0.02(\mathrm{n}=8)$ & $0.38 \pm 0.04^{\mathrm{a}, \mathrm{b}}(\mathrm{n}=8)$ & $0.25 \pm 0.05^{\mathrm{a}-\mathrm{c}}(\mathrm{n}=9)$ \\
FS $(\%)$ & Pre-op & $48.9 \pm 1.7(\mathrm{n}=10)$ & $49.4 \pm 1.2(\mathrm{n}=10)$ & $50.7 \pm 2.7(\mathrm{n}=10)$ \\
& Post-op & $49.3 \pm 1.9(\mathrm{n}=8)$ & $31.2 \pm 2.1^{\mathrm{a}, \mathrm{b}}(\mathrm{n}=8)$ & $40.4 \pm 4.3^{\mathrm{a}-\mathrm{c}}(\mathrm{n}=9)$ \\
LVEF $(\%)$ & Pre-op & $81.3 \pm 1.6(\mathrm{n}=10)$ & $80.3 \pm 2.4(\mathrm{n}=10)$ & $80.9 \pm 2.6(\mathrm{n}=10)$ \\
& Post-op & $80.0 \pm 3.7(\mathrm{n}=8)$ & $58.2 \pm 6.8^{\mathrm{a}, \mathrm{b}}(\mathrm{n}=8)$ & $64.5 \pm 9.8^{\mathrm{a}, \mathrm{b}}(\mathrm{n}=9)$ \\
\hline
\end{tabular}

Data are presented as the mean $\pm \mathrm{SD} .{ }^{\mathrm{a}} \mathrm{P}<0.01 \mathrm{vs}$. preoperative in the same group; ${ }^{\mathrm{b}} \mathrm{P}<0.01 \mathrm{vs}$. postoperative in the sham group; ${ }^{\mathrm{c}} \mathrm{P}<0.01 \mathrm{vs}$. postoperative in the CME group. LVEDD, left ventricular end-diastolic dimension; LVESD, left ventricular end-systolic dimension; LVESV, left ventricular end-systolic volume; LVEDV, left ventricular end-diastolic volume; FS, fractional shortening; LVEF, left ventricular ejection fraction; CME, coronary thrombotic microembolism; DIL, diltiazem.

Table II. Hemodynamic measurements.

\begin{tabular}{lrcccc}
\hline Group & $\mathrm{n}$ & $\operatorname{LVSP}(\mathrm{mmHg})$ & $\operatorname{LVEDP}(\mathrm{mmHg})$ & $\mathrm{dp} / \mathrm{dtmax}(\mathrm{mmHg} / \mathrm{s})$ & $-\mathrm{dp} / \mathrm{dtmax}(\mathrm{mmHg} / \mathrm{s})$ \\
\hline Sham & 9 & $150.1 \pm 9.8$ & $5.4 \pm 2.9$ & $5605 \pm 693$ & $-5034 \pm 394$ \\
CME & 9 & $104.3 \pm 9.6^{\mathrm{a}}$ & $15.3 \pm 2.8^{\mathrm{a}}$ & $2986 \pm 236^{\mathrm{a}}$ & $-2612 \pm 239^{\mathrm{a}}$ \\
CME+DIL & 10 & $106.0 \pm 7.3^{\mathrm{a}}$ & $10.8 \pm 2.0^{\mathrm{a}, \mathrm{c}}$ & $3407 \pm 359^{\mathrm{a}, \mathrm{b}}$ & $-2905 \pm 316^{\mathrm{a}}$ \\
\hline
\end{tabular}

Data are presented as the mean $\pm \mathrm{SD}$. ${ }^{\mathrm{a}} \mathrm{P}<0.01 \mathrm{vs}$. the sham group; ${ }^{\mathrm{b}} \mathrm{P}<0.05,{ }^{\mathrm{c}} \mathrm{P}<0.01 \mathrm{vs}$. the $\mathrm{CME}$ group. LVSP, left ventricular systolic pressure; LVEDP, left ventricular end-diastolic pressure; dp/dtmax, the maximum rate of increase of the LV systolic pressure; -dp/dtmax, the maximum rate of decrease of the LV systolic pressure; CME, coronary thrombotic microembolism; DIL, diltiazem.

Transthoracic echocardiography. Preoperative values were comparable between the CME and CME+DIL groups. Four weeks postoperatively, the LVEDV was significantly lower, while the FS and LVEF were significantly higher, in the CME+DIL group compared with the CME group (Table I).

Hemodynamic measurements. In the $3 \mathrm{~h}$ group, dp/dtmax and -dp/dtmax were significantly higher, while LVEDP was significantly lower, in the CME+DIL group than in the CME group (Table II).

Levels of c-TNI at 6 and 24 hostinjection. c-TNI levels were significantly reduced in the CME+DIL group compared with those in the CME group at 6 and $24 \mathrm{~h}$ post-automicrothrombotic particulate injection (Fig. 2).

Levels of plasma $v W F$ and ET-1 postinjection. Plasma vWF is regarded as a good indicator of endothelial dysfunction and has been shown to contribute to the activation of the coagulation cascade $(28,29)$. Plasma vWF levels were significantly lower at $3 \mathrm{~h}$ following the injection of post-automicrothrombotic particulates in the CME+DIL group than in the CME

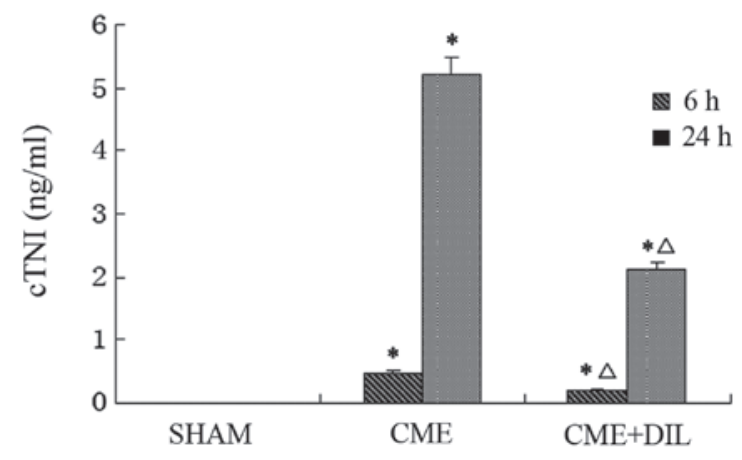

Figure 2. Serum c-troponin I (c-TNI) levels postinjection. c-TNI levels at 6 and $24 \mathrm{~h}$ after injection were significantly lower in the CME+DIL group than in the CME group. Data are presented as the mean $\pm \mathrm{SD} .{ }^{*} \mathrm{P}<0.01$ vs. the sham group; ${ }^{\triangle} \mathrm{P}<0.01$ vs. the $\mathrm{CME}$ group. $\mathrm{CME}$, coronary thrombotic microembolism; DIL, diltiazem.

group (Table III). Levels of ET-1, the endothelium-derived vasoconstrictor peptide, increase in response to myocardial ischemia and infarction (30,31). Plasma ET-1 levels at $3 \mathrm{~h}, 24 \mathrm{~h}$ and 7 days after the injection of post-automicrothrombotic 
Table III. Plasma vWF and ET-1 levels postinjection.

Time postinjection

\begin{tabular}{|c|c|c|c|c|c|}
\hline Group & Variable & $3 \mathrm{~h}$ & $24 \mathrm{~h}$ & 7 days & 28 days \\
\hline Sham & $\begin{array}{l}\mathrm{vWF}(\mathrm{ng} / \mathrm{ml}) \\
\mathrm{ET}-1(\mathrm{pg} / \mathrm{ml})\end{array}$ & $\begin{array}{l}6.08 \pm 0.29(\mathrm{n}=9) \\
50.2 \pm 0.24(\mathrm{n}=9)\end{array}$ & $\begin{array}{l}5.98 \pm 0.25(\mathrm{n}=9) \\
52.2 \pm 0.26(\mathrm{n}=9)\end{array}$ & $\begin{array}{l}5.94 \pm 0.26(\mathrm{n}=9) \\
51.2 \pm 0.23(\mathrm{n}=9)\end{array}$ & $\begin{array}{l}6.02 \pm 0.29(\mathrm{n}=8) \\
52.2 \pm 0.29(\mathrm{n}=8)\end{array}$ \\
\hline CME & $\begin{array}{l}\text { vWF }(\mathrm{ng} / \mathrm{ml}) \\
\text { ET-1 (pg/ml) }\end{array}$ & $\begin{array}{l}7.80 \pm 0.58^{\mathrm{a}}(\mathrm{n}=9) \\
93.6 \pm 1.24^{\mathrm{a}}(\mathrm{n}=9)\end{array}$ & $\begin{array}{r}6.61 \pm 0.46^{\mathrm{a}}(\mathrm{n}=10) \\
154.2 \pm 2.46^{\mathrm{a}}(\mathrm{n}=10)\end{array}$ & $\begin{array}{c}6.10 \pm 0.41(\mathrm{n}=10) \\
114.8 \pm 2.46^{\mathrm{a}}(\mathrm{n}=10)\end{array}$ & $\begin{array}{l}6.23 \pm 0.35(\mathrm{n}=9) \\
84.0 \pm 1.35^{\mathrm{a}}(\mathrm{n}=9)\end{array}$ \\
\hline CME+DIL & $\begin{array}{l}\text { vWF (ng/ml) } \\
\text { ET-1 (pg/ml) }\end{array}$ & $\begin{array}{l}6.95 \pm 0.59^{\mathrm{a}, \mathrm{b}}(\mathrm{n}=10) \\
73.2 \pm 0.48^{\mathrm{a}, \mathrm{b}}(\mathrm{n}=10)\end{array}$ & $\begin{array}{c}6.31 \pm 0.49(\mathrm{n}=9) \\
100.2 \pm 0.49^{\mathrm{a}, \mathrm{b}}(\mathrm{n}=9)\end{array}$ & $\begin{array}{l}6.06 \pm 0.36(\mathrm{n}=10) \\
78.6 \pm 0.76^{\mathrm{a}, \mathrm{b}}(\mathrm{n}=10)\end{array}$ & $\begin{array}{l}6.13 \pm 0.39(n=9) \\
74.8 \pm 1.68^{\mathrm{a}}(\mathrm{n}=9)\end{array}$ \\
\hline
\end{tabular}

Data are presented as the mean $\pm \mathrm{SD} .{ }^{\mathrm{a}} \mathrm{P}<0.01$ vs. the sham group; ${ }^{\mathrm{b}} \mathrm{P}<0.01$ vs. the CME group. vWF, von Willebrand factor; ET-1, endothelin-1; CME, coronary thrombotic microembolism; DIL, diltiazem.

Table IV. Leukocyte infiltration postinjection (leukocytes $/ \mathrm{mm}^{2}$ ).

Time postinjection

\begin{tabular}{llll}
\cline { 2 - 4 } Group & \multicolumn{1}{c}{$24 \mathrm{~h}$} & \multicolumn{1}{c}{7 days } & 28 days \\
\hline Sham & $158 \pm 42(\mathrm{n}=9)$ & $160 \pm 42(\mathrm{n}=9)$ & $157 \pm 22(\mathrm{n}=8)$ \\
CME & $930 \pm 126^{\mathrm{a}}(\mathrm{n}=10)$ & $836 \pm 105^{\mathrm{a}}(\mathrm{n}=10)$ & $160 \pm 24(\mathrm{n}=9)$ \\
CME+DIL & $652 \pm 112^{\mathrm{a}, \mathrm{b}}(\mathrm{n}=9)$ & $322 \pm 66^{\mathrm{a}, \mathrm{b}}(\mathrm{n}=10)$ & $159 \pm 22(\mathrm{n}=9)$ \\
\hline
\end{tabular}

Data are presented as the mean $\pm \mathrm{SD} .{ }^{\mathrm{a}} \mathrm{P}<0.01$ vs. sham group; ${ }^{\mathrm{b}} \mathrm{P}<0.01$ vs. CME group. CME, coronary thrombotic microembolism; DIL, diltiazem.

particulates were also significantly lower in the CME+DIL group than in the CME group (Table III).

NF evaluation at 3 h postinjection. The NF was evaluated by thioflavin $\mathrm{S}$ (blue fluorescence represented the perfused zone and non-fluorescent areas represented the NF when examined under ultraviolet light at a $365-\mathrm{nm}$ wavelength). The NF/LV ratio was significantly lower in the CME+DIL group than in the CME group (5.6 \pm 2.5 vs. $11.2 \pm 2.7 \%, \mathrm{P}<0.01$; Fig. 3).

\section{Light microscope analyses}

$H \& E$ staining at 3 h postinjection. Three hours postinjection, red thrombi were identified in $18.2 \pm 4.5 \%$ of coronary arterioles with diameters $<100 \mu \mathrm{m}$ in the CME group, compared with $10.4 \pm 2.5 \%$ in the CME+DIL group ( $\mathrm{P}<0.01$; Fig. $4 \mathrm{~B}$ and $\mathrm{C})$.

Carstair's staining at $3 \mathrm{~h}$ postinjection. Different colors in Carstair's staining represented different components of the thrombosis in arterioles; bright red for fibrin, gray-blue to navy blue for platelets, bright blue for collagen, red for muscle and clear yellow for red blood cells. Three hours postinjection, evidence of thrombosis was observed in the CME and CME+DIL groups. The major components of thrombosis were fibrins and platelets, and there was also red cell accumulation in the vascular lumen (Fig. 4E and F).

HBFP staining at 3 h post injection. HBFP staining was used to detect early myocardial ischemia or infarct regions. The normal myocardium was stained yellow or yellow- brown, and the ischemic or necrotic myocardial tissue was stained cardinal red. The ischemic area (IA) was calculated using the following formula: IA $(\%)=$ IA/area of field of vision $x$ 100. The IA was $6.3 \pm 1.2 \%$ in the CME group and reduced to $3.3 \pm 1.2 \%$ in the $\mathrm{CME}+\mathrm{DIL}$ group $(\mathrm{P}<0.01$; Fig. $4 \mathrm{H}$ and I).

Masson staining 28 days postoperatively. Masson staining was carried out in the 28 days postinjection group. Cardiomyocytes were stained red and collagen stained blue. The collagen volume fraction $(\mathrm{CVF}=$ area of collagen/area of the field of vision $\mathrm{x} 100 \%$ ) was measured. The CVF was significantly lower in the CME+DIL group (Fig. 4L) than in the CME group (Fig. 4K; $5.38 \pm 1.46$ vs. $2.60 \pm 1.07 \%$, P $<0.01$ ).

Inflammatory cell infiltration. At $24 \mathrm{~h}$ postinjection, coagulative necrosis occurred in the microinfarct zone and polymorphonuclear leukocyte infiltration was observed around the blocked vessel in the CME group (Fig. 5B). Seven days postinjection, the majority of infiltrated leukocytes were macrophages and leukomonocytes in the CME+DIL group (Fig. 5C). The leukocyte counts were significantly lower in the CME+DIL group than in the CME group $24 \mathrm{~h}$ and 7 days postoperatively (Table IV).

Immunohistochemical staining. At $3 \mathrm{~h}$ postinjection, VSMA- $\alpha$ was expressed in vascular smooth muscle cells and the vascular smooth muscle was dyed claybank in order to count the arterioles (10-100 $\mu \mathrm{m})$. Fig. 6 shows arterioles with different diameters in the CME and CME+DIL groups. 

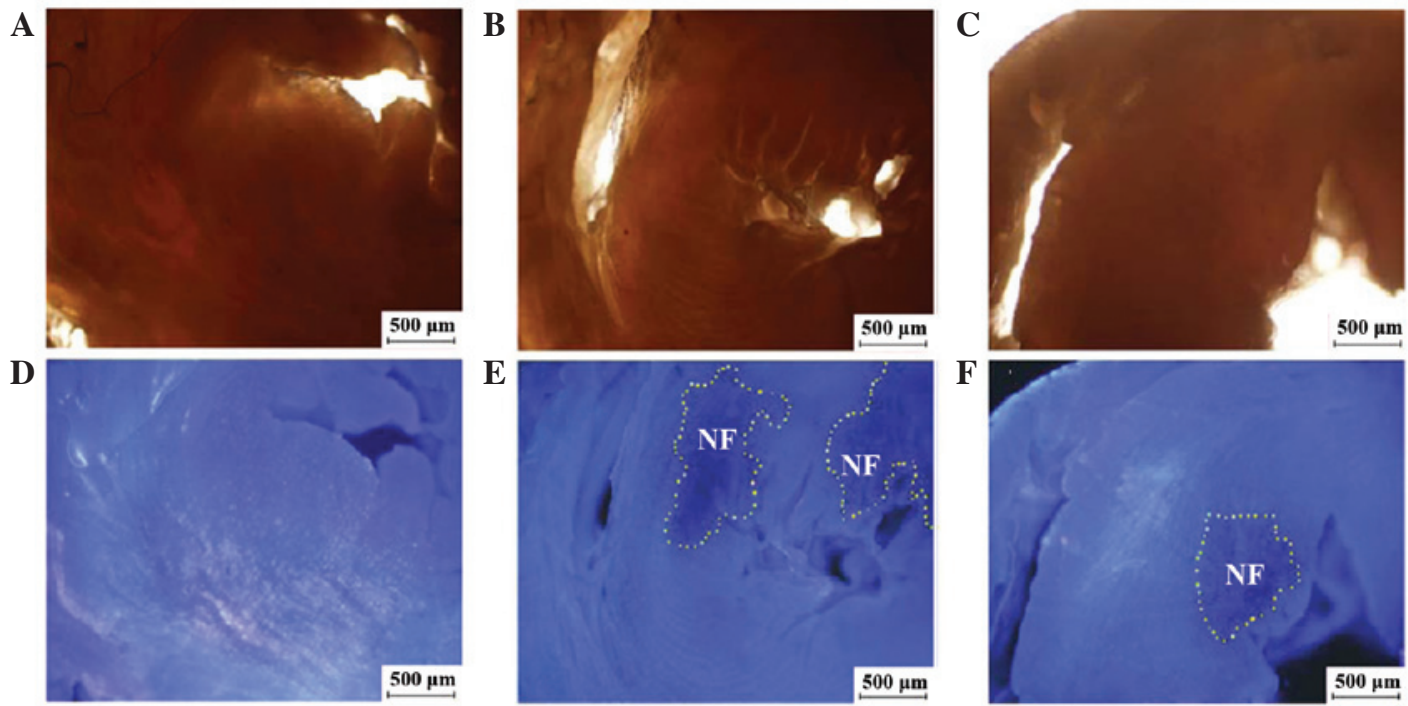

Figure 3. No-flow zone (NF) evaluation at $3 \mathrm{~h}$ postinjection. (A-C) Optical microscope images used as background references for the sham, CME and CME+DIL groups, respectively. Under ultraviolet light, the NF was identified as the region deficient in fluorescence of thioflavin-S in the (D) sham, (E) CME and (F) CME+DIL groups (magnification, x40). The yellow dotted line delineates the NF. CME, coronary thrombotic microembolism; DIL, diltiazem.

A

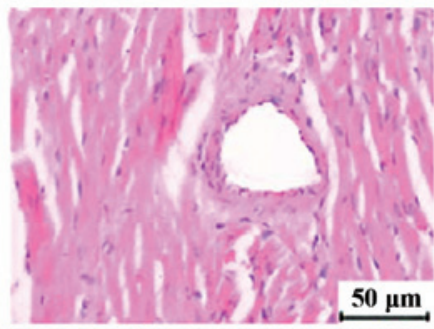

D

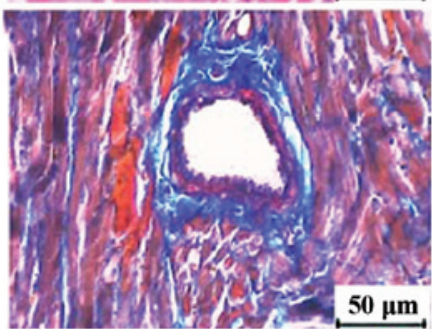

G

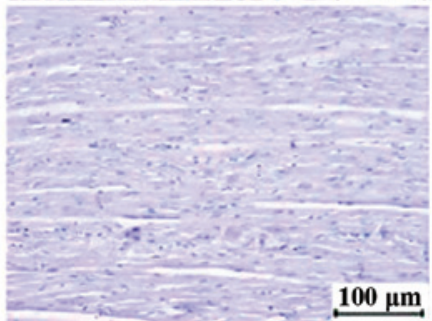

J

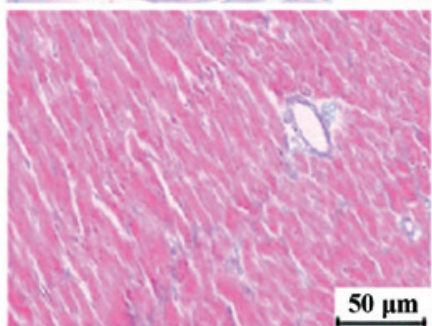

B

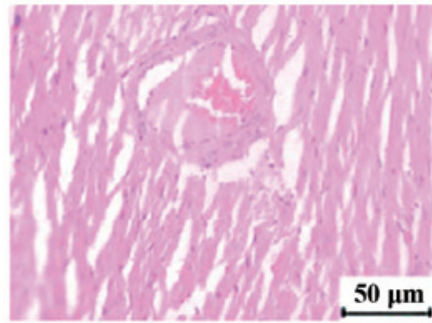

E

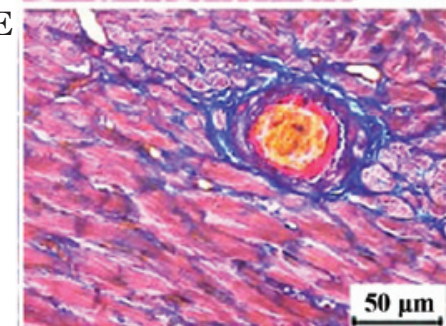

H

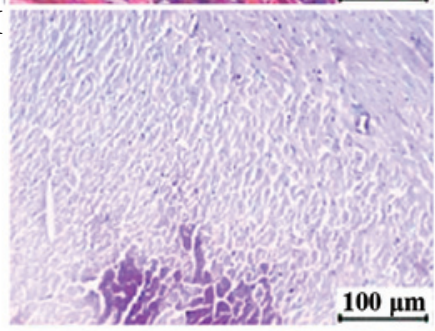

K

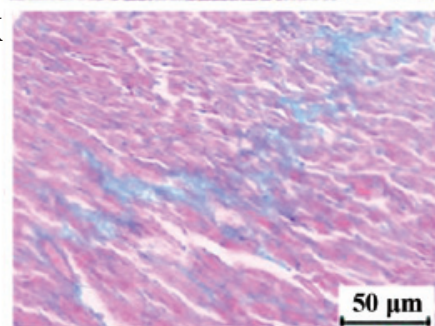

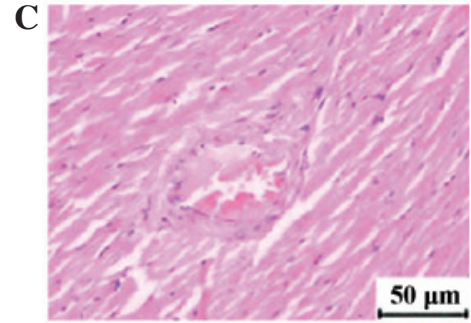

F

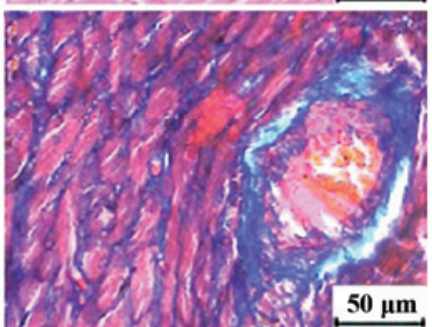

I

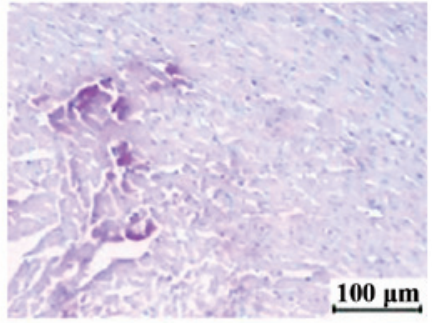

L

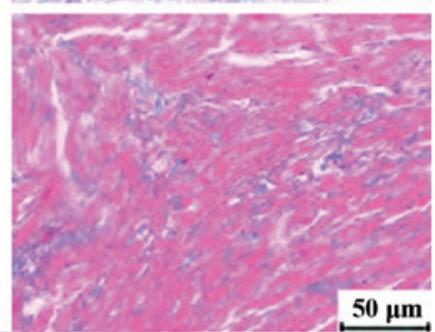

Figure 4. Light microscopic analyses. In H\&E-stained slices (magnification, x200), red thrombosis was not observed in arterioles of (A) the sham group, but was observed in the (B) CME and (C) CME+DIL groups. (D-F) In the sham, CME and CME+DIL groups, respectively, Carstair's staining (magnification, x200) showed that the major components of thrombosis in the CME group were fibrins (bright red), platelets (gray-blue to navy blue) and red cells (yellow). (G-I) In the sham, CME and CME+DIL groups, respectively, HBFP staining (magnification, x100) showed cardinal red regions $3 \mathrm{~h}$ postinjection in the CME and CME+DIL groups. (J-L) In the sham, CME and CME+DIL groups, respectively, Masson staining at 4 weeks postinjection (magnification, x200) showed increased collagen in the CME group and decreased collagen deposition in the CME+DIL group. H\&E, hematoxylin and eosin; CME, coronary thrombotic microembolism; DIL, diltiazem; HBFP, hematoxylin basic fuchsin picric acid. 
Table V. Number of arterioles at $3 \mathrm{~h}$ postinjection $\left(\mathrm{s} / \mathrm{mm}^{2}\right)$.

\begin{tabular}{lccr}
\hline & \multicolumn{3}{c}{ Group } \\
\cline { 2 - 4 } Arteriole diameter & Sham & CME & CME+DIL \\
\hline $10-20 \mu \mathrm{m}$ & $2.61 \pm 0.18(\mathrm{n}=9)$ & $2.15 \pm 0.26^{\mathrm{b}}(\mathrm{n}=9)$ & $2.4 \pm 0.19^{\mathrm{c}}(\mathrm{n}=10)$ \\
$20-50 \mu \mathrm{m}$ & $0.70 \pm 0.06(\mathrm{n}=9)$ & $0.32 \pm 0.10^{\mathrm{b}}(\mathrm{n}=9)$ & $0.59 \pm 0.14^{\mathrm{d}}(\mathrm{n}=10)$ \\
$50-100 \mu \mathrm{m}$ & $0.30 \pm 0.03(\mathrm{n}=9)$ & $0.28 \pm 0.05(\mathrm{n}=9)$ & $0.32 \pm 0.04(\mathrm{n}=10)$ \\
\hline
\end{tabular}

Data are presented as the mean $\pm \mathrm{SD} .{ }^{\mathrm{a}} \mathrm{P}<0.05,{ }^{\mathrm{b}} \mathrm{P}<0.01 \mathrm{vs}$. the sham group; ${ }^{\mathrm{C}} \mathrm{P}<0.05,{ }^{\mathrm{d}} \mathrm{P}<0.01 \mathrm{vs}$. the CME group. CME, coronary thrombotic microembolism; DIL, diltiazem.
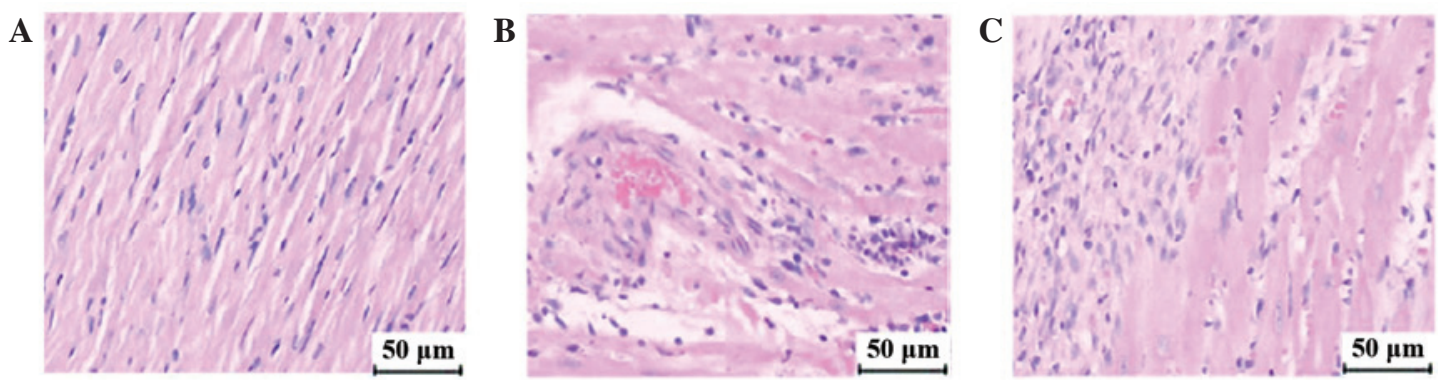

Figure 5. Inflammatory cell infiltration by hematoxylin and eosin (H\&E) staining. (A) The sham group. (B) Increased polymorphonuclear leukocyte infiltration was observed in the microinfarct zone in the CME group at $24 \mathrm{~h}$ postinjection. (C) Increased macrophage and leukomonocyte infiltration was observed near the microinfarct zone in the CME+DIL group at 7 days postinjection (magnification, $\mathrm{x} 200$ ). CME, coronary thrombotic microembolism; DIL, diltiazem.

A

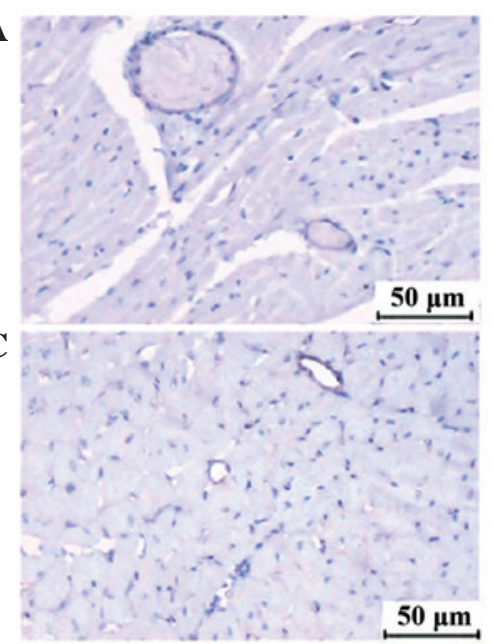

B

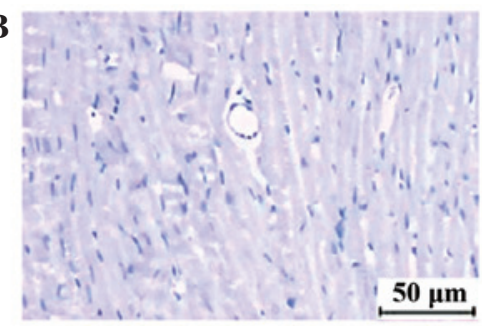

D

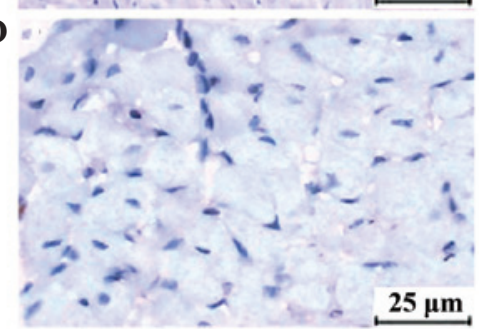

Figure 6. Immunohistochemical staining. Positive expression of vascular smooth muscle $\alpha$-actin in vascular smooth muscle cells (magnification, $\mathrm{x} 200$ ). Two arterioles of different diameters were observed in the (A) CME and (C) CME+DIL groups (magnification, x200). An example of (B) a venule (magnification, $\mathrm{x} 200$ ) and (D) a capillary (magnification, $\mathrm{x} 400$ ) in the CME+DIL group. CME, coronary thrombotic microembolism; DIL, diltiazem.

Immunohistochemical staining analysis indicated that the number of arterioles with a diameter in the range of $10-50 \mu \mathrm{m}$, particularly arterioles with diameters of 20-50 $\mu \mathrm{m}$, was significantly higher in the CME+DIL group than in the CME group at $3 \mathrm{~h}$ postinjection (Table $\mathrm{V}$ ).

Western blot analysis. The myocardial protein expression levels of TNF- $\alpha$ and IL- 6 were significantly downregulated in the CME+DIL group compared with those in the CME group at various time-points postinjection (Fig. 7).

\section{Discussion}

The present study demonstrated that the injection of automicrothrombotic particulates into the aorta of male Sprague Dawley rats successfully induced CME, arteriolar thrombosis, histologically-confirmed ischemic regions and NF. This confirmed the pathological changes that were shown in this model in a previous study (9).

Results from this model demonstrated that the components of the thrombosis in coronary arterioles were fibrin, 
A
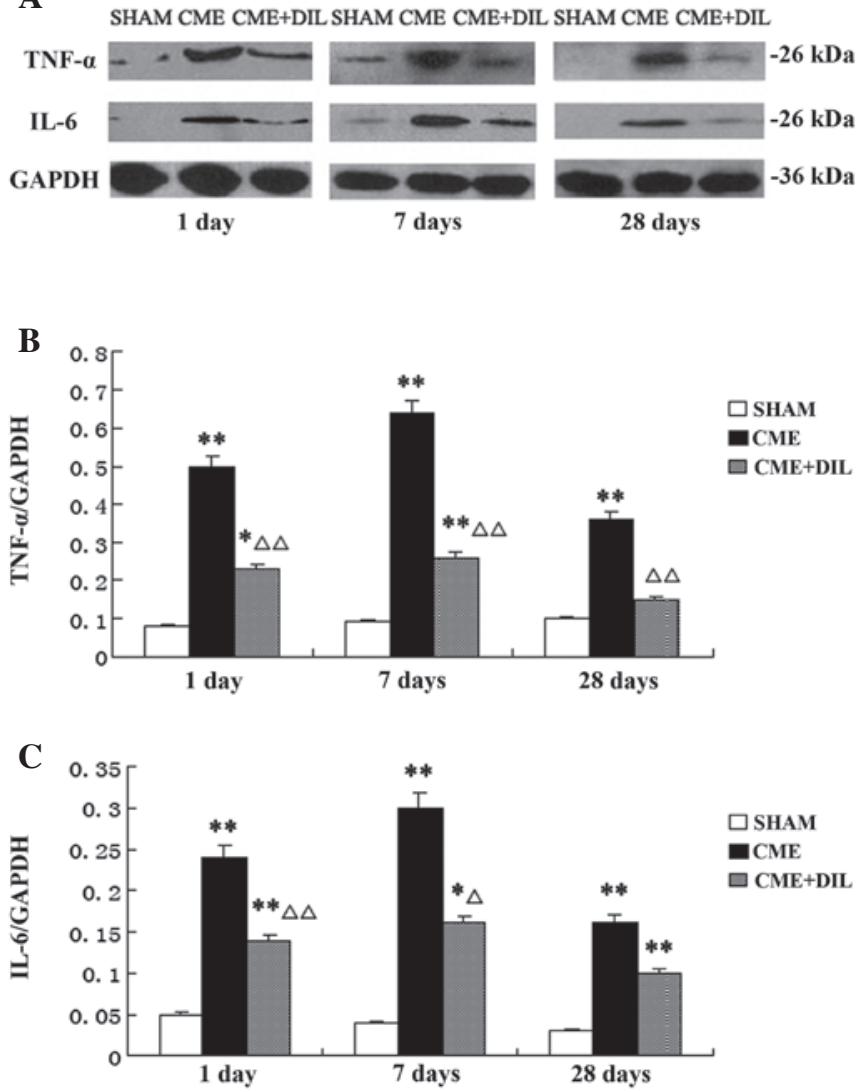

Figure 7. Western blot analysis of TNF- $\alpha$ and IL-6. (A) Expression levels of TNF- $\alpha$ and IL- 6 at different time-points. (B) Representation of TNF- $\alpha / G A P D H$ at different time-points. (C) Representation of IL-6/GAPDH at different time-points. Data are presented as the mean $\pm \mathrm{SD} .{ }^{*} \mathrm{P}<0.05,{ }^{* *} \mathrm{P}<0.01$ vs. the sham group. ${ }^{\triangle} \mathrm{P}<0.05,{ }^{\triangle} \mathrm{P}<0.01$ vs. the $\mathrm{CME}$ group. TNF- $\alpha$, tumor necrosis factor $\alpha$; IL-6, interleukin-6; CME, coronary thrombotic microembolism; DIL, diltiazem.

aggregated platelets and red blood cells, indicating the presence of vessels that were obstructed by automicrothrombotic particulates and newly formed thrombosis in situ. Increased vWF and ET-1 levels, indicators of endothelial function (32), at $3 \mathrm{~h}$ postinjection in CME rats indicated that microthrombotic particulates may also induce microvascular endothelial injury. Acute myocardial injury was demonstrated by increased c-TnI levels at 6 and $24 \mathrm{~h}$ and myocardial infarctlets in HBFP-stained myocardium at $3 \mathrm{~h}$ post-automicrothrombotic particulate injection in this model. Immunohistochemical staining analysis indicated that the number of $10-50 \mu \mathrm{m}$ diameter arterioles (particularly 20-50 $\mu \mathrm{m}$ ) was significantly reduced in the CME group at $3 \mathrm{~h}$ postinjection compared with the number in the sham rats. Therefore, the injection of automicrothrombotic particulates induced not only arteriolar thrombosis, but also arteriolar spasm. Moreover, increased serum c-TnI levels and myocardial leukocyte infiltration at early time-points postinjection and prolonged inflammatory responses indicated by increased myocardial TNF- $\alpha$ and IL 6 expression resembled typical inflammatory responses post-ischemia (33). This finding is in line with previous reports showing that an inflammatory reaction was the most significant mechanism resulting in systolic heart failure in CME and that the inflammatory mediator TNF- $\alpha$ may be causal in contractile dysfunction following CME (34-38). The interactions between microem- bolism, plaque fissuring, arrhythmia and dysfunction have been summarized previously $(5,9,12)$. Thus, there may be a correlation between microembolism and the NF phenomenon in that increased myocardial collagen content demonstrated by histology and reduced cardiac function shown by transthoracic echocardiography at 4 weeks may be the sequential changes induced by microembolism. Briefly, coronary microembolism/ coronarymicrothrombosis may result in endothelial damage/ dysfunction as well as arteriolar spasm, leading to coronary vascular resistance increase, no reflow, microinfarctlets inflammatory reaction, myocardial remodeling and cardiac dysfunction.

The aim of this study was to explore the feasibility of using the present rat CME model to reflect the therapeutic effects of clinically effective medication on CME injury. The effects of intravenous diltiazem were therefore evaluated in this animal model. Diltiazem is a calcium channel antagonist that inhibits myocardial calcium entry by blockade of voltage-dependent membrane calcium channels. Although calcium channel antagonists all inhibit calcium channel conductance, they exhibit considerable selectivity of action in terms of vasodilation, negative inotropic and chronotropic effects $(37,39)$. Previous clinical studies have shown that calcium antagonists may attenuate microvascular spasm by relaxing small vascular smooth muscle $(7,8,40)$, and intravascular application of diltiazem may attenuate coronary artery spasm in patients with microvascular angina $(19,20)$. In the current study, it was demonstrated that intravenous diltiazem $(1 \mathrm{mg} / \mathrm{ml}, 50 \mu \mathrm{g} / \mathrm{min} / \mathrm{kg})$ administered at $5 \mathrm{~min}$ post-automicrothrombotic particulate injection for 175 min improved cardiac function, attenuated the reduction in the number of arterioles (diameter 10-50 $\mu \mathrm{m}$ ) and reduced the NF in the present CME model, possibly through attenuating microvascular spasm. Moreover, diltiazem also reduced myocardial ischemia, endothelia dysfunction and inflammatory responses, as indicated by changes in c-TnI, plasma vWF and ET-1 levels, as well as the myocardial protein expression levels of TNF- $\alpha$ and IL-6. It was also demonstrated that the number of red thrombi reduced immediately after diltiazem application in H\&E-stained myocardial tissue, the ischemic area in HBFP-stained myocardial samples was reduced $3 \mathrm{~h}$ postinjection and the CVF in Masson-stained myocardial samples was reduced 28 days postinjection. These results are thus in line with previous findings showing that treatment of the ischemic myocardium with calcium channel blockers attenuates ultrastructural myocardial injury $(41,42)$, decreases calcium influx $(42,43)$ and improves postischemic left ventricular segmental function (43-48). The NF area was reduced but did not disappear completely in the CME+DIL group. This may indicate that part of the capillary network was already undergoing necrotic changes and was unable to be recovered following diltiazem treatment. However, diltiazem did improve automicrothrombotic particulate-induced functional no-reflow by reducing myocardial spasm (47).

Large animal CME models have been widely used in microembolism research $(49,50)$. The rat CME model used in the present study differs from the large animal CME models in the following respects: i) This model mimicked in vivo arteriole blockade by various sizes of microthrombi following atherosclerotic plaque rupture; ii) the components of automicrothrombotic particulates are similar to thrombi in vivo, 
including fibrin, platelets and blood corpuscle; iii) automicrothrombotic particulates are easy to obtain and do not require elaborate equipment in the laboratory; iv) rat models are more economical compared with large animal models; and v) rat hearts are smaller and the entire heart may be easily sampled with few histological sections.

Notably, it is difficult to define the exact mechanism of action for diltiazem and to differentiate the anti-vasospasm and -vasoconstriction effects of diltiazem with the data available for this model. Therefore, further studies are required to explore these points.

In conclusion, this animal model mimicked certain pathological changes induced by coronary embolization that have been observed in clinical patients with acute coronary syndromes and in patients who have undergone revascularization procedures (fibrinolytics or transcatheter recanalization during surgical or percutaneous procedures, or prior embolization before procedures). Intravenous diatiazem reduced automicrothrombotic particulate injection-induced myocardial injury. Thus, this model may be used to test the effects of drugs that have the potential to attenuate CME and arteriolar thrombosis-induced myocardial injury.

\section{Acknowledgements}

This study was supported by the National Natural Science Foundation of China (81270266).

\section{References}

1. Abdelmeguid AE, Topol EJ, Whitlow PL, Sapp SK and Ellis SG: Significance of mild transient release of creatine kinase-MB fraction after percutaneous coronary interventions. Circulation 94: 1528-1536, 1996.

2. Califf RM, Abdelmeguid AE, Kuntz RE, et al: Myonecrosis after revascularization procedures. J Am Coll Cardiol 31: 241-251, 1998.

3. Herrmann J, Haude M, Lerman A, et al: Abnormal coronary flow velocity reserve after coronary intervention is associated with cardiac marker elevation. Circulation 103: 2339-2345, 2001.

4. Mehran R, Dangas G, Mintz GS, et al: Atherosclerotic plaque burden and CK-MB enzyme elevation after coronary interventions: intravascular ultrasound study of 2256 patients Circulation 101: 604-610, 2000.

5. Erbel R and Heusch G: Coronary microembolization. J Am Coll Cardiol 36: 22-24, 2000.

6. Golino P, Piscione F, Benedict CR, et al: Local effect of serotonin released during coronary angioplasty. N Engl J Med 330 $523-528,1994$.

7. Wilson RF, Laxson DD, Lesser JR and White CW: Intense microvascular constriction after angioplasty of acute thrombotic coronary arterial lesions. Lancet 1: 807-811, 1989.

8. Piana RN, Paik GY, Moscucci M, et al: Incidence and treatment of 'no-reflow' after percutaneous coronary intervention. Circulation 89: 2514-2518, 1994.

9. Gu Y, Bai Y, Wu J, Hu L and Gao B: Establishment and characterization of an experimental model of coronary thrombotic microembolism in rats. Am J Pathol 177: 1122-1130, 2010.

10. Heusch G, Kleinbongard P, Böse D, et al: Coronary microembolization: from bedside to bench and back to bedside. Circulation 120: 1822-1836, 2009.

11. Herrmann J: Peri-procedural myocardial injury: 2005 update. Eur Heart J 26: 2493-2519, 2005.

12. Heusch G, Schulz R, Haude M and Erbel R: Coronary microembolization. J Mol Cell Cardiol 37: 23-31, 2004.

13. Lee KW and Norell MS: Management of 'no-reflow' complicating reperfusion therapy. Acute Card Care 10: 5-14, 2008.

14. Pasceri V, Patti G and Di Sciascio G: Prevention of myocardial damage during coronary intervention. Cardiovasc Hematol Disord Drug Targets 6: 77-83, 2006.
15. Valero SJ, Moreno R, Reyes RM, et al: Pharmacological approach of no-reflow phenomenon related with percutaneous coronary interventions. Cardiovasc Hematol Agents Med Chem 6: 125-129, 2008

16. Kleinbongard P, Konorza T, Böse D, et al: Lessons from human coronary aspirate. J Mol Cell Cardiol 52: 890-896, 2012.

17. Werner GS, Lang K, Kuehnert H and Figulla HR: Intracoronary verapamil for reversal of no-reflow during coronary angioplasty for acute myocardial infarction. Catheter Cardiovasc Interv 57: 444-451, 2002.

18. McIvor ME, Undemir C, Lawson J and Reddinger J: Clinical effects and utility of intracoronary diltiazem. Cathet Cardiovasc Diagn 35: 287-293, 1995.

19. Sütsch G, Oechslin E, Mayer I and Hess OM: Effect of diltiazem on coronary flow reserve in patients with microvascular angina. Int J Cardiol 52: 135-143, 1995.

20. Zheng ZF, Pu XQ, Yang TL, et al: Effects of intracoronary diltiazem on no-reflow phenomenon after emergent percutaneous coronary intervention in patients with acute myocardial infarction. Zhong Nan Da Xue Xue Bao Yi Xue Ban 31: 917-920, 2006 (In Chinese).

21. Brown C: Blood collection from the tail of a rat. Lab Anim (NY) 35: 24-25, 2006

22. Kudo M, Aoyama A, Ichimori S and Fukunaga N: An animal model of cerebral infarction. Homologous blood clot emboli in rats. Stroke 13: 505-508, 1982.

23. Grossman W: Pressure measurement. In: Grossman's Cardiac Catheterition, Angiography, and Intervention. Baim DS (ed). 7th edition. Lippincott Williams \& Wilkins, Philadelphia, pp139-141, 2006.

24. Genda S, Miura T, Miki T, Ichikawa $\mathrm{Y}$ and Shimamoto K: $\mathrm{K}$ (ATP) channel opening is an endogenous mechanism of protection against the no-reflow phenomenon but its function is compromised by hypercholesterolemia. J Am Coll Cardiol 40: 1339-1346, 2002 .

25. Eitzman DT, Bodary PF, Shen Y, et al: Fabry disease in mice is associated with age-dependent susceptibility to vascular thrombosis. J Am Soc Nephrol 14: 298-302, 2003.

26. Fujita M, Fujioka Y and Ommura Y: Histopathological diagnosis of early stages of myocardial infarction - applications of the improved hematoxylin basic fuchsin picric acid (HBFP) staining method to human autopsy hearts. Hokkaido Igaku Zasshi 60: 313-320, 1985 (In Japanese).

27. Goldner J: A modification of the Masson trichrome technique for routine laboratory purposes. Am J Pathol 14: 237-243, 1938.

28. Blann AD: Plasma von Willebrand factor, thrombosis, and the endothelium: the first 30 years. Thromb Haemost 95: 49-55, 2006.

29. With Notø AT, Bøgeberg Mathiesen E, Amiral J, Vissac AM and Hansen JB: Endothelial dysfunction and systemic inflammation in persons with echolucent carotid plaques. Thromb Haemost 96: 53-59, 2006.

30. Stewart DJ, Kubac G, Costello KB and Cernacek P: Increased plasma endothelin-1 in the early hours of acute myocardial infarction. J Am Coll Cardiol 18: 38-43, 1991.

31. Tønnessen T, Giaid A, Saleh D, Naess PA, Yanagisawa M and Christensen G: Increased in vivo expression and production of endothelin-1 by porcine cardiomyocytes subjected to ischemia. Circ Res 76: 767-772, 1995.

32. Ruggeri ZM: Von Willebrand factor, platelets and endothelial cell interactions. J Thromb Haemost 1: 1335-1342, 2003.

33. Bonvini RF, Hendiri T and Camenzind E: Inflammatory response post-myocardial infarction and reperfusion: a new therapeutic target? Eur Heart J Suppl 7 (Suppl I): I27-I36, 2005.

34. Skyschally A, Schulz R, Haude M, Erbel R and Heusch G: Coronary microembolization: perfusion-contraction mismatch secondary to myocardial inflammation. Herz 29: 777-781, 2004 (In German).

35. Dörge H, Neumann T, Behrends M, et al: Perfusion-contraction mismatch with coronary microvascular obstruction: role of inflammation. Am J Physiol Heart Circ Physiol 279: H2587-H2592, 2000.

36. Dörge H, Schulz R, Belosjorow S, et al: Coronary microembolization: the role of TNF-alpha in contractile dysfunction. J Mol Cell Cardiol 34: 51-62, 2002.

37. Triggle DJ and Swamy VC: Calcium antagonists. Some chemical-pharmacologic aspects. Circ Res 52: I17-I28, 1983.

38. Kleinbongard P, Heusch G and Schulz R: TNFalpha in atherosclerosis, myocardial ischemia/reperfusion and heart failure. Pharmacol Ther 127: 295-314, 2010. 
39. Fleckenstein A: History of calcium antagonists. Circ Res 52: I3-I16, 1983.

40. Beltrame JF, Turner SP, Leslie SL, Solomon P, Freedman SB and Horowitz JD: The angiographic and clinical benefits of mibefradil in the coronary slow flow phenomenon. J Am Coll Cardiol 44: 57-62, 2004.

41. Hamm CW and Opie LH: Protection of infarcting myocardium by slow channel inhibitors. Comparative effects of verapamil, nifedipine, and diltiazem in the coronary-ligated, isolated working rat heart. Circ Res 52: I129-I138, 1983.

42. Nayler WG, Ferrari R and Williams A: Protective effect of pretreatment with verapamil, nifedipine and propranolol on mitochondrial function in the ischemic and reperfused myocardium. Am J Cardiol 46: 242-248, 1980.

43. Bourdillon PD and Poole-Wilson PA: The effects of verapamil, quiescence, and cardioplegia on calcium exchange and mechanical function in ischemic rabbit myocardium. Circ Res 50: 360-368, 1982.

44. Przyklenk K and Kloner RA: Effect of verapamil on postischemic 'stunned' myocardium: importance of the timing of treatment. J Am Coll Cardiol 11: 614-623, 1988.

45. Bush LR, Buja LM, Tilton G, et al: Effects of propranolol and diltiazem alone and in combination on the recovery of left ventricular segmental function after temporary coronary occlusion and long-term reperfusion in conscious dogs. Circulation 72: 413-430, 1985
46. Higgins AJ and Blackburn KJ: Prevention of reperfusion damage in working rat hearts by calcium antagonists and calmodulin antagonists. J Mol Cell Cardiol 16: 427-438, 1984.

47. Galiuto L: Optimal therapeutic strategies in the setting of post-infarct no reflow: the need for a pathogenetic classification. Heart 90: 123-125, 2004.

48. Kleinbongard P, Baars T and Heusch G: Calcium antagonists in myocardial ischemia/reperfusion - update 2012. Wien Med Wochenschr 162: 302-310, 2012.

49. Huang Y, Hunyor S, Jiang L, et al: Remodeling of the chronic severely failing ischemic sheep heart after coronary microembolization: functional, energetic, structural, and cellular responses. Am J Physiol Heart Circ Physiol 286: 2141-2150, 2004.

50. Gill RM, Jones BD, Corbly AK, et al: Exhaustion of the FrankStarling mechanism in conscious dogs with heart failure induced by chronic coronary microembolization. Life Sciences 79 : 536-544, 2006. 